\title{
Gryllus bimaculatus extract protects against lipopolysaccharide and palmitate-induced production of proinflammatory cytokines and inflammasome formation
}

\author{
WOO-JAE PARK ${ }^{1,2}$ and JUNG-SOON HAN ${ }^{3}$ \\ ${ }^{1}$ Department of Biochemistry, College of Medicine; ${ }^{2}$ Department of Health Science and Technology, \\ Gachon Advanced Institute for Health Science and Technology, Gachon University, Incheon 21999; \\ ${ }^{3}$ Research Institute of Human Ecology, Korea University, Seoul 02841, Republic of Korea
}

Received October 6, 2020; Accepted December 8, 2020

DOI: $10.3892 / \mathrm{mmr} .2021 .11845$

\begin{abstract}
Inflammation and the inflammasome complex formation are associated with numerous diseases, and palmitates or lipopolysaccharides (LPS) have been identified as potential links between these disorders. Recently, edible insects such as the Gryllus bimaculatus (GB) and the larva of Tenebrio molitor have emerged as alternative food sources. In the present study, the effect of GB on LPS- or palmitate-induced production of inflammatory cytokines, the formation of the inflammasome complex, reactive oxygen species (ROS) generation, endoplasmic reticulum (ER) stress and cell death was investigated in RAW264.7 cells. The results revealed that GB extract downregulated the production of inflammatory cytokines (such as TNF- $\alpha$, IL-1 $\beta$ and IL- 6 ). Since the role of the MAP kinase and NF- $\mathrm{kB}$ signalling pathways in the production of inflammatory cytokines is well established, the translocation of p65 into the nucleus and the phosphorylation of IкB and MAP kinases were further examined. Both these processes were upregulated following LPS and palmitate treatment, but they were inhibited by the GB extract. Moreover, GB extract decreased LPS/palmitate-induced inflammasome complex formation (assessed via analysing the levels of the apoptosis-associated
\end{abstract}

Correspondence to: Professor Woo-Jae Park, Department of Biochemistry, College of Medicine, Gachon University, Getberllo 155, Incheon 21999, Republic of Korea

E-mail: ooze@gachon.ac.kr

Professor Jung-Soon Han, Research Institute of Human Ecology, Korea University, Anamlo 145, Seoul 02841, Republic of Korea

E-mail: yohwa0960@korea.ac.kr

Abbreviations: ASC, apoptosis-associated speck-like protein containing a caspase-recruitment domain; ER, endoplasmic reticulum; GB, Gryllus bimaculatus; LPS, lipopolysaccharide; NLRP3, NOD-like receptor family pyrin domain containing 3 ; ROS, reactive oxygen species

Key words: GB, inflammation, MAP kinase, NF-кB, inflammasome, ER stress, ROS, cell death speck-like protein containing a caspase-recruitment domain, NOD-like receptor family pyrin domain containing 3 , cleaved caspase- 1 and IL-1 $\beta$ ), the generation of ROS, ER stress and cell death. Treatment with SB203580 (a p38 inhibitor), SP600125 (a JNK inhibitor) and pyrrolidinedithiocarbamate ammonium (an NF- $\mathrm{KB}$ inhibitor) decreased the production of inflammatory cytokines, as well as helped in the recovery of LPS/palmitate-induced cell death. Overall, GB extract served an inhibitory role in LPS/palmitate-induced inflammation via inhibiting the MAP kinase and NF- $\mathrm{KB}$ signalling pathways, inflammasome complex formation, ROS generation, ER stress and cell death.

\section{Introduction}

Inflammation is induced in response to various stimuli such as palmitate and lipopolysaccharides (LPS). Palmitate, a C16 saturated fatty acid, plays an important role in low dose inflammation in obesity and many other metabolic diseases (1).LPS, an important component of the outer membrane of gram-negative bacteria, is the key immune activator against bacterial infection. LPS can bind to TLR4 (toll-like receptor 4) and activate the MAP kinase and NF- $\mathrm{BB}$ pathway, which can subsequently increase the expression of various pro-inflammatory cytokines such as TNF- $\alpha$, IL- $1 \beta$, IL-6 and interferon- $\beta$. Even though palmitate is not a TLR4 agonist (2), it can activate TLR4, MAP kinase, and the NF- $\kappa B$ pathway (3). Furthermore, palmitate treatment not only increases the generation of reactive oxygen species (ROS) in the mitochondria, but also increases calcium release from the endoplasmic reticulum (ER) leading to mitochondrial dysfunction and cell death (1). LPS also has similar effects that induce ROS generation, mitochondrial dysfunction and cell death (4).

The inflammasome could be triggered by many signals such as potassium efflux, ROS generation in mitochondria, etc. (5). The NOD-like receptor pyrin domain containing 3 (NLRP3), the apoptosis-associated speck-like protein containing a caspase-recruitment domain (ASC), and the pro-caspase-1 are assembled, leading to auto-activation of caspase-1 upon its cleavage which subsequently cleaves its substrates, IL-1 $\beta$ and IL-18 (5). IL-1 $\beta$, a pro-inflammatory cytokine, plays an 
important role in inflammatory responses while IL-18 activates inflammatory responses as well as protects against invading various microorganisms (6). The inflammasome complex formation is induced in response to various stimuli such as LPS (7), palmitate (8), and anthrax toxin (9); it is also formed in case of many inflammatory disease such as alcoholic hepatitis (10), liver injury (11), lung injury (12), and several cancers (13). Thus, formation of the inflammasome complex is a novel process involved in regulating many inflammatory responses.

Gryllus bimaculatus (GB) is an edible insect that can be used as an alternative protein source. Previously, GB extract has been shown to inhibit inflammation in several disease models such as that of chronic arthritis (14) and alcohol-induced steatohepatitis (15). Furthermore, GB has exhibited glucose lowering effect in streptozotocin-induced diabetic mice (16). Therefore, GB could be used as a functional food source for patients with chronic inflammation or metabolic diseases.

In this study, we evaluated the effects of GB extract on LPS or palmitate-induced production of pro-inflammatory cytokines, inflammasome formation, ER stress, ROS generation, and cell death.

\section{Materials and methods}

Materials. The following materials were purchased as indicated: i) LPS, palmitate, SB203580, SP600125, PD98059, 2',7'-dichlorofluorescin diacetate (DCF-DA) and anti- $\alpha$-tubulin antibody (T9026) from Sigma-Aldrich; Merck KGaA; ii) anti-p65 (8242), anti-phospho-IкB (2859), anti-Lamin B2 (13823), anti-phosphor-p38 (4511), anti-p38 (8690), anti-phospho-JNK (9255), anti-JNK (9252), anti-phospho-ERK (4370), anti-ERK (4695), anti-phospho-protein kinase RNA-like ER kinase (PERK; 3179), anti-PERK (3192), anti-phospho-eukaryotic initiation factor $2 \alpha$ (eif $2 \alpha ; 3597)$, anti-eif $2 \alpha$ (5324), anti-caspase-3 (9664), anti-cleaved-PARP1 (5625) and NLRP3 (15101) antibodies from Cell Signalling Technology, Inc.; iii) anti-caspase-1 (sc-56036) and anti-ACS (sc-22514-R) antibodies from Santa Cruz Biotechnology, Inc.; iv) IL-1 $\beta$ antibody (NB600-633) from Novus Biologicals; v) pyrrolidinedithiocarbamate ammonium (PDTC) from Biovision; vi) Alexa-Fluor 488 antibody (A-11008) from Thermo Fisher Scientific, Inc.; vii) 4',6-Dia midino-2-phenylindole dihydrochloride (DAPI) from Merck (D9542); and viii) anti-mouse-HRP (horseradish peroxidase, 115-036-003) and anti-rabbit-HRP (111-035-003) antibodies from Jackson Laboratory.

Gryllus bimaculatus extract. GB extract was generated as per the previous study (15). Briefly, it was dried, ground, extracted overnight using $70 \%$ ethanol, and evaporated. Prepared samples were dissolved in PBS and frozen at $-20^{\circ} \mathrm{C}$ until further use.

Fatty acid analysis. GB were snap frozen at $-40^{\circ} \mathrm{C}$ by lyophilization for three days (Freezone 4.5; Labconco) and ground into fine powder. Heptane $(1 \mathrm{ml}), 2 \mathrm{ml}$ methylation mixture (MeOH/benzene/dimethoxypropane/sulphuric acid in the ratio of 39:20:5:2, v/v), and $0.2 \mathrm{mg}$ of pentadecanoic acid (internal standard) were added to the GB samples and shaken gently at $80^{\circ} \mathrm{C}$ for $2 \mathrm{~h}$ (BioFree Co.). Then, the samples were cooled down to room temperature and the supernatant containing fatty acid methyl esters were centrifuged for $1 \mathrm{~min}$. The fatty acid composition in the supernatant was determined using the Agilent 7890A (Agilent Technologies, Inc.) and DB-23 $60 \mathrm{~mm}$, $0.25 \mathrm{~mm}, 0.25 \mu \mathrm{m}$ (Agilent Technologies, Inc.). The injection volume was $1 \mu \mathrm{l}$ with 1:50 split mode. The flow rates were as follows: hydrogen flame gas, $35 \mathrm{ml} / \mathrm{min}$; helium carrier gas, $35 \mathrm{ml} / \mathrm{min}$, and mixed gas, $350 \mathrm{ml} / \mathrm{min}$. The corresponding column oven temperatures were as follows: $50^{\circ} \mathrm{C}, 1 \mathrm{~min}$, $25^{\circ} \mathrm{C} / \mathrm{min}$ to $200^{\circ} \mathrm{C}, 3^{\circ} \mathrm{C} / \mathrm{min}$ to $230^{\circ} \mathrm{C}$, and $18 \mathrm{~min}$ as previously described (17).

In vitro LPS and palmitate treatment. RAW264.7 cells were grown in Dulbecco's modified Eagle's medium (HyClone) supplemented with $10 \%$ fetal bovine serum and $1 \%$ penicillin/streptomycin (HyClone). LPS (50 ng/ml) or $250 \mu \mathrm{M}$ palmitate were used to induce inflammation as previously described $(7,18,19)$ and $50 \mu \mathrm{g} / \mathrm{ml}$ LPS or $2 \mathrm{mM}$ palmitate were used to induce cell death $(20,21)$.

Enzyme-linked immunosorbent assay (ELISA). At $30 \mathrm{~h}$, after pre-treatment of RAW264.7 cells with 100-200 $\mu \mathrm{g} / \mathrm{ml}$ GB extract and another $18 \mathrm{~h}$ co-incubation with $50 \mathrm{ng} / \mathrm{ml}$ LPS or $250 \mu \mathrm{M}$ palmitate, TNF- $\alpha$, IL- $1 \beta$ and IL- 6 levels in the culture medium were measured using ELISA kits (TNF- $\alpha$, IL-1 $\beta$ and IL-6 Mouse ELISA kits; Komabiotech) as per manufacturer's instructions.

Western blotting. RAW264.7 cells were lysed using RIPA buffer (50 mM Tris-Cl, pH 7.5, 150 mM NaCl, 1\% Nonidet P-40, 0.5\% sodium deoxycholate, and $0.1 \%$ SDS) containing protease and phosphatase inhibitors (Sigma-Aldrich; Merck KGaA). The lysates were then incubated on ice for $30 \mathrm{~min}$ and centrifuged $\left(10,000 \mathrm{x} \mathrm{g}, 10 \mathrm{~min}, 4^{\circ} \mathrm{C}\right)$; protein levels in the supernatant were measured using the Protein Assay Dye Reagent (Bio-Rad Laboratories). Using SDS-PAGE, $50 \mu \mathrm{g}$ proteins were separated on $8-15 \%$ SDS polyacrylamide gels and transferred to nitrocellulose membranes (Bio-Rad Laboratories). Membranes were blocked using $5 \%$ bovine serum albumin (Sigma-Aldrich; Merck KGaA) in TBST (TBS with $0.1 \%$ Tween-20) for $1 \mathrm{~h}$ and incubated with primary antibodies (1:1,000 dilution) overnight at $4^{\circ} \mathrm{C}$. Secondary antibodies were incubated for $1 \mathrm{~h}$ at room temperature. Protein bands were detected using the EzWestLumi Plus Reagents (ATTO Corporation) on the Chemidoc MP imaging system (Bio-Rad Laboratories).

Separation of nuclear and cytoplasmic fractions. The nuclear and cytoplasmic fractions were separated as previously described (22). Briefly, RAW264.7 cells were lysed using a fractionation buffer (50 mM HEPES, pH 7.4, $10 \mathrm{mM} \mathrm{KCl,} 1 \mathrm{mM}$ EDTA, $1 \mathrm{mM}$ EGTA, $1 \mathrm{mM}$ dithiothreitol, and 0.1\% NP-40) containing protease and phosphatase inhibitors (Sigma-Aldrich; Merck KGaA). After 30 min incubation on ice, the lysates were centrifuged $\left(4,000 \times \mathrm{g}, 5 \mathrm{~min}, 4^{\circ} \mathrm{C}\right)$, and the pellet was further sonicated in lysis buffer (20 mM HEPES, pH 7.4, $150 \mathrm{mM} \mathrm{NaCl}$, $12.5 \mathrm{mM}$ glycerophosphate, $1.5 \mathrm{mM} \mathrm{MgCl}_{2}, 2 \mathrm{mM}$ EGTA, $10 \mathrm{mM} \mathrm{NaF}, 2 \mathrm{mM}$ dithiothreitol, $1 \mathrm{mM} \mathrm{Na} \mathrm{VO}_{4}, 0.5 \%$, and Triton X-100) containing protease and phosphatase inhibitors to obtain the nuclear fraction. The supernatant was centrifuged $\left(12,500 \times \mathrm{g}, 5 \mathrm{~min}, 4^{\circ} \mathrm{C}\right)$ to obtain the cytoplasmic fraction.

Immunohistochemistry. RAW264.7 cells were co-treated with GB extract (100 or $200 \mu \mathrm{g} / \mathrm{ml})$ and palmitate $(250 \mu \mathrm{M})$ or LPS 


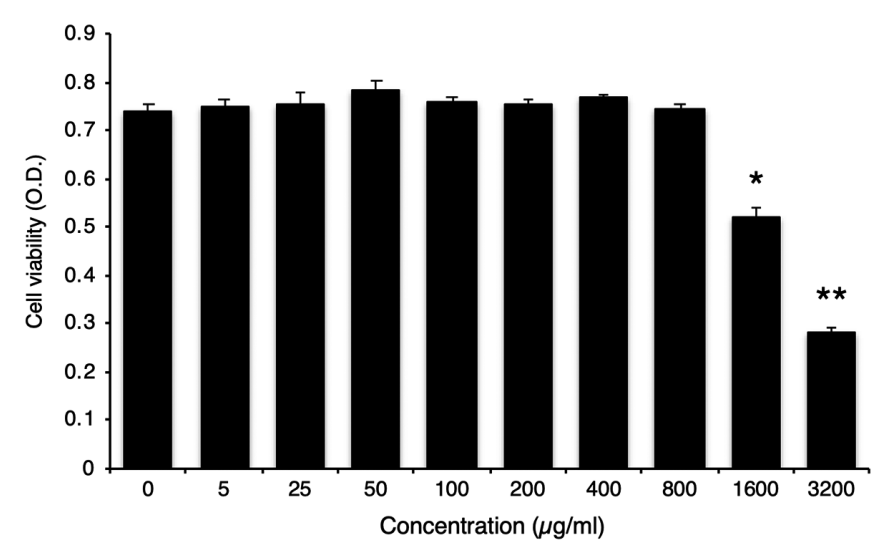

Figure 1. Effect of GB extract on cell viability. After treating the cells with various concentration of GB extract for $48 \mathrm{~h}$, cell viability was examined. The values are expressed as the mean \pm SEM $(n=3)$. ${ }^{*} \mathrm{P}<0.05$ and ${ }^{* *} \mathrm{P}<0.01$ vs. control $(0 \mu \mathrm{g} / \mathrm{ml})$. GB, Gryllus bimaculatus; OD, optical density.

(50 $\mathrm{ng} / \mathrm{ml}$ ) for $18 \mathrm{~h}$, after which the cells were fixed with cold methanol for $10 \mathrm{~min}$. Fixed cells were blocked with horse serum for $1 \mathrm{~h}$ and then incubated with p65 antibody (1:200) overnight at $4^{\circ} \mathrm{C}$. After washing, Alexa-Fluor 488 secondary antibody (1:500) was incubated with the cells at room temperature in the dark for $1 \mathrm{~h}$. DAPI was used to label nuclei for $10 \mathrm{~min}$, and cells were mounted with vector shield mount media solution (Vector Laboratories). The p65 fluorescence and DAPI signals were viewed using a confocal microscope (LSM 710; Carl Zeiss).

Reverse transcription-quantitative PCR (RT-qPCR). RT-qPCR was performed as previously described (23). Briefly, total mRNA was extracted from the RAW264.7 cells using the RNAiso Plus reagent (Takara) and cDNA was synthesized using the PrimeScript ${ }^{\mathrm{TM}}$ RT Reagent kit with gDNA Eraser (Takara). qPCR was performed using the SYBR ${ }^{\circledR}$ Premix Ex Taq ${ }^{\mathrm{TM}}$ II, ROX Plus (Takara) in a Bio-Rad CFX96 System (Bio-Rad). Relative gene expression was calculated using the $2^{-\Delta \Delta \mathrm{Ct}}$ method (24). Primer sequences are listed in Table I.

MTT assay. Cell death was evaluated using the MTT (3-(4,5,-dimethylthiazol-2,5-diphenyl tetrazolium bromide) assay (25). RAW264.7 cells were seeded onto 96-well plates at a density of $5 \times 10^{4}$ cells/ well. After treatment with either chemicals (SB203580, SP600125, PDTC) or GB extract, the cells were treated with MTT solution $(0.5 \mathrm{mg} / \mathrm{ml}$ final concentration) and further incubated for $4 \mathrm{~h}$. The assay was terminated by adding $50 \mu \mathrm{l}$ dimethyl sulfoxide (DMSO) to dissolve the purple formazan crystals. Solubilized formazan was quantified spectrophotometrically at $540 \mathrm{~nm}$.

Detection of ROS. RAW264.7 cells were pre-treated with GB extract followed by either LPS or palmitate treatment. To quantify ROS, DCF-DA was added at a final concentration of $10 \mu \mathrm{M}$ and incubated for $30 \mathrm{~min}$ in the dark. The fluorescent intensity of DCF was measured at $485 \mathrm{~nm}$ (excitation) and $535 \mathrm{~nm}$ (emission) using a confocal microscope (LSM 710).

Statistical analysis. All the experiments were repeated independently in triplicates and the data was expressed as mean \pm standard error of the mean (SEM). Statistical
Table I. Primers used for quantitative PCR.

\begin{tabular}{llr}
\hline Gene & \multicolumn{1}{c}{ Primer sequences } & (Ref.) \\
\hline TNF- $\alpha$ & F: 5'-CTGTAGCCCACGTCGTAGC-3' & $(22)$ \\
(mouse) & R: 5'-TTGAGATCCATGCCGTTG-3' \\
IL-1 $\beta$ & F: 5'-TGTAATGAAAGACGGCACACC-3' \\
(mouse) & R: 5'-TCTTCTTTGGGTATTGCTTGG-3' \\
IL-6 & F: 5'-TCCAGTTGCCTTCTTGGGAC-3' \\
(mouse) & R: 5'-GTACTCCAGAAGACCAGAGG-3' \\
GAPDH & F: 5'-CGACTTCAACAGCAACTCCCACTCTTCC-3' (22) \\
(mouse) & R: 5'-TGGGTGGTCCAGGGTTTCTTACTCCTT-3'
\end{tabular}

F, forward; R, reverse.

Table II. Fatty acid composition of the Gryllus bimaculatus extract.

Fatty acid Concentration $(\mathrm{mg} / \mathrm{g})$

Caproic acid (hexanoic acid)

0.376

Lauric acid (dodecanoic acid)

0.195

Myristic acid (tetradecanoic acid)

1.660

Palmitic acid (hexadecanoic acid)

52.162

Palmitoleic acid

3.876

Margaric acid (heptadecanoic acid)

0.708

Stearic acid (octadecanoic acid)

15.159

Oleic acid

60.570

Linoleic acid

60.411

Alpha-linolenic acid (ALA)

1.170

Arachidic acid (eicosanoic acid)

1.608

significance was calculated using one-way ANOVA followed by Tukey's post-hoc test (GraphPad Prism 6.0; GraphPad Software, Inc.). $\mathrm{P}<0.05$ was considered to indicate a statistically significant difference.

\section{Results}

Fatty acids composition of Gryllus bimaculatus extract. First, we examined the fatty acid composition of the GB extract. It was found to contain two major saturated fatty acids, palmitic acid $(52.2 \mathrm{mg} / \mathrm{g})$ and stearic acid $(15.2 \mathrm{mg} / \mathrm{g})$ and two main unsaturated fatty acids, oleic acid $(60.5 \mathrm{mg} / \mathrm{g})$ and linoleic acid $(60.4 \mathrm{mg} / \mathrm{g})$ as listed in Table II.

Gryllus bimaculatus extract has an inhibitory effect on LPS or palmitate-induced production of inflammatory cytokines. We examined the cell viability in vitro using various concentrations of the GB extract; less than $800 \mu \mathrm{g} / \mathrm{ml}$ of the GB extract did not affect the viability of RAW264.7 cells (Fig. 1). Previous studies showed that $40-100 \mu \mathrm{g} / \mathrm{ml}$ of the GB extract could reduce nitrite, TNF- $\alpha$, and IL- 6 in the LPS-treated kupffer cells (15). Therefore, we used 100 and $200 \mu \mathrm{g} / \mathrm{ml}$ of GB in this study. To examine if GB extract has any anti-inflammatory effect upon LPS and palmitate treatment, the cells were pre-treated with GB extract and then with 

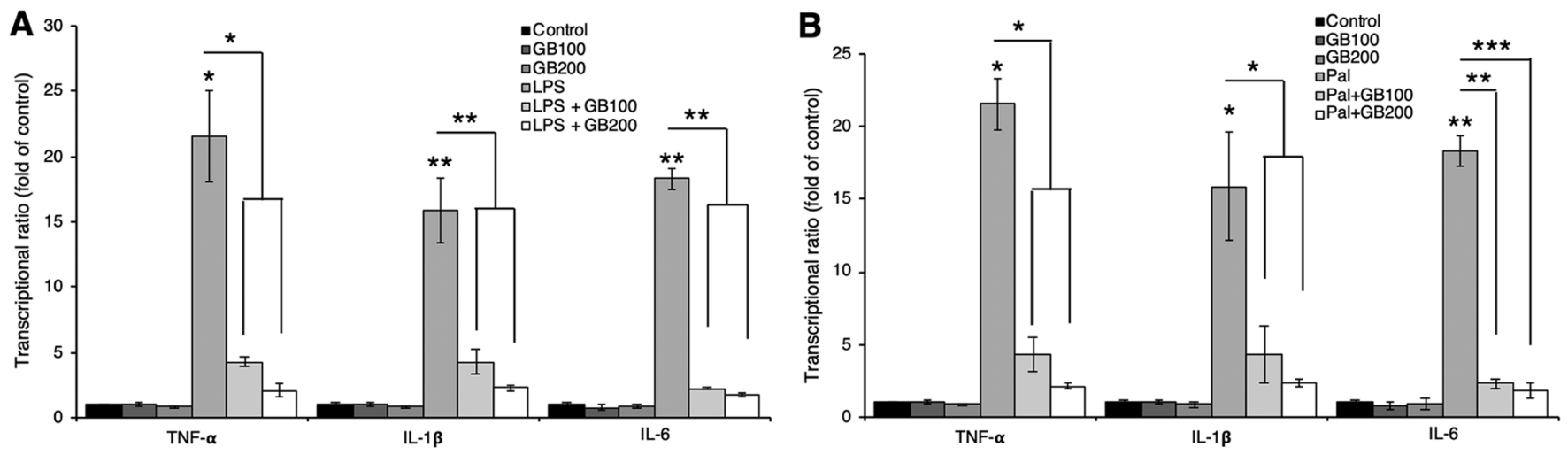

Figure 2. Effect of GB extract on LPS- or Pal-induced production of pro-inflammatory cytokines. Reverse transcription-quantitative PCR of proinflammatory cytokines (TNF- $\alpha$, IL-1 $\beta$ and IL-6) after co-treatment with (A) LPS (50 ng/ml) and GB extract (100 and $200 \mu \mathrm{g} / \mathrm{ml}$ ) or (B) Pal and GB extract. The values are expressed as the mean \pm SEM $(\mathrm{n}=3) .{ }^{*} \mathrm{P}<0.05 ;{ }^{* *} \mathrm{P}<0.01 ;{ }^{* * *} \mathrm{P}<0.001$. GB, Gryllus bimaculatus; LPS, lipopolysaccharide; Pal, palmitate.

either LPS or palmitate. LPS or palmitate treatment induced pro-inflammatory cytokine production including TNF- $\alpha$, IL-1 $\beta$, and IL-6 while GB extract pre-treatment inhibited the pro-inflammatory cytokine mRNA levels (Fig. 2A and B) and their secretion (Fig. 3A-C).

Gryllus bimaculatus extract has an inhibitory effect on LPS or palmitate-induced activation of $N F-\kappa B$ and MAP kinase. Previous studies showed that MAP kinases and NF- $\mathrm{KB}$ signalling pathways play an important role in the production of LPS or palmitate-induced inflammatory cytokines $(18,22,26)$. Therefore, both these pathways, NF- $\kappa \mathrm{B}$ signalling (p65 translocation into nucleus and phosphorylation of $\mathrm{I} \kappa \mathrm{B}$ ) and MAP kinases (p38, JNK, ERK) were examined. LPS or palmitate treatment elevated $\mathrm{p} 65$ translocation, IкB phosphorylation (Fig. 4A and B) as well as phosphorylation of MAP kinases (p38, JNK, ERK) (Fig. 4C); though they were reduced upon pre-treatment with GB extract (Fig. 4A-C). To further examine if MAP kinase and NF- $\mathrm{BB}$ activation involve any pro-inflammatory cytokine production, we pre-treated the cells with either p38 inhibitor (SB203580), JNK inhibitor (SP600125), ERK inhibitor (PD98059), or NF- $\kappa$ B inhibitor (PDTC). A reversal in the LPS and palmitate induced elevation of pro-inflammatory cytokine production was observed with respect to $\mathrm{p} 38$, JNK, and NF- $\mathrm{kB}$ inhibitors, but not ERK inhibitor (Fig. 5A-C).

Gryllus bimaculatus extract has an inhibitory effect on LPS or palmitate-induced NLRP3 inflammasome activation. Previous studies showed that, both palmitate and LPS induce NLRP3 inflammasome activation $(7,27)$, we therefore examined the inflammasome components in this study- NLRP3, ASC, pro-caspase-1, cleaved-caspase1 (c-caspase-1), and IL-1 $\beta$. LPS or palmitate treatment increased the expression of all the components while GB extract reduced them, suggesting that the GB extract can reduce inflammasome formation (Fig 6A and B). Interestingly, GB extract did not affect expression of pro-caspase-1.

Gryllus bimaculatus extract has an inhibitory effect on LPS or palmitate-induced ROS generation and endoplasmic reticulum (ER) stress. Since both LPS and palmitate are known to increase ROS generation $(1,4,28)$, we examined if GB extract affects ROS generation upon LPS or palmitate treatment. As expected, both LPS and palmitate increased ROS generation, while GB reduced it (Fig. 7A). Furthermore, GB also reduced the LPS or palmitate-induced ER stress markers- PERK and eif $2 \alpha$ phosphorylation (Fig. 7B and C).

Gryllus bimaculatus extract has an inhibitory effect on LPS or palmitate-induced cell death. Finally, we examined the role of GB extract in cell death upon exposure to high doses of LPS or palmitate. LPS or palmitate treatment induced cell death with increased cleavage of caspase-3 (c-caspase-3) and PARP1 (c-PARP1). Co-treatment with GB extract reduced cell death and also decreased cleavage of caspase-3 and PARP1 (Fig. 8A). Since GB extract reduced phosphorylation of MAP kinases (p38, JNK) and NF-kB pathway, we also treated the cells with these inhibitors and examined cell death. These inhibitors were observed to reduce cell death as well as caspase- 3 and PARP1 cleavage (Fig. 8B). Therefore, GB appears to have a protective role in LPS or palmitate-induced cell death.

\section{Discussion}

Inflammation plays an important role in many diseases such as arthritis, steatohepatitis and cancers; macrophages have a central role in inflammation. In the present study, we examined the effect of GB extract on LPS or palmitate-induced production of pro-inflammatory cytokines and formation of the inflammasome complex in RAW264.7 cells. GB extract exhibited a protective role in production of pro-inflammatory cytokines through inhibition of MAP kinase and NF- $\mathrm{kB}$ signalling pathway. IкB is phosphorylated by activating IкB kinase in response to an inflammatory stimulus followed by translocation of an activated p65 from the cytosol to the nucleus (29); activated p65 in the nucleus in turn increases the transcription of pro-inflammatory cytokines. MAP kinases (p38, JNK, ERK) play diverse roles in many cellular processes ranging from proliferation to differentiation and cell death. Among the three MAP kinases, only p38 and JNK reduced the production of all the pro-inflammatory cytokines, suggesting that ERK pathway may be playing a minor role in the process. Furthermore, GB also had an inhibitory role in the formation of inflammasome 

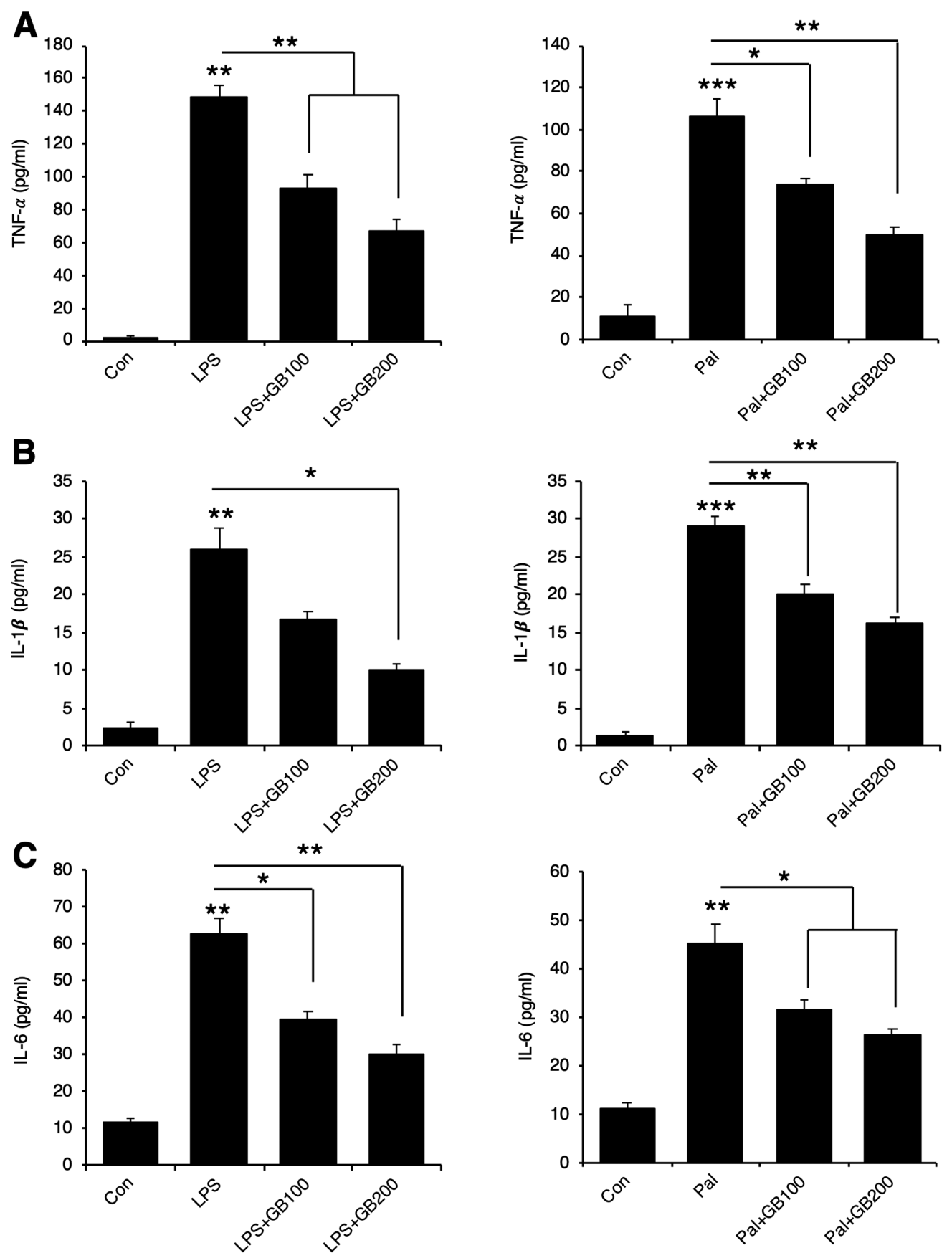

Figure 3. Effect of GB extract on LPS- or Pal-induced release of TNF- $\alpha$, IL- $1 \beta$ and IL-6. After co-treatment with GB extract (100 and 200 $\mu$ g/ml) and Pal $(250 \mu \mathrm{M})$ or LPS (50 ng/ml), (A) TNF- $\alpha$, (B) IL-1 $\beta$, and (C) IL-6 expression levels were measured in RAW264.7 cell culture medium using ELISA kits. The values are expressed as the mean $\pm \mathrm{SEM}(\mathrm{n}=3) .{ }^{*} \mathrm{P}<0.05 ;{ }^{* *} \mathrm{P}<0.01 ;{ }^{* * *} \mathrm{P}<0.001$. GB, Gryllus bimaculatus; LPS, lipopolysaccharide; Pal, palmitate; Con, control.

complex. Inflammasome is equipped by the formation of NLRP3, ASC and pro-caspase-1 complex (6). GB extract reduced the expression of NLRP3, ASC, c-caspase- 1 and IL-1 $\beta$ upon LPS or palmitate treatment. NLRP3 expression is low but can be increased by TLR activation in a NF- $\kappa B$ dependent manner (6). Since GB extract has inhibitory effects on NF- $\kappa B$ pathway, it can also reduce inflammasome formation.

ROS generation upon palmitate treatment is due to the partial inhibition of mitochondrial complexes I and III (1). LPS also inhibited mitochondrial complex I (30) and increased ROS generation (4). GB extract reduced both LPS-induced and palmitate-induced ROS generation. Oleic acid has been shown to downregulate palmitate-induced ROS generation and cell death, in a CD36 dependent manner (31); therefore, oleic acid in GB extract might improve palmitate-induced mitochondrial complex I inhibition and reduce ROS generation. Furthermore, oleic acid and linoleic acid also have protective effects against palmitate-induced ER stress (32-34). These unsaturated fatty acids are known to inhibit inflammation via several mechanisms. For example, linoleic acid and oleic acid prevent inflammation by activating PPAR- $\gamma(35,36)$ and inhibiting $\mathrm{NF}-\kappa \mathrm{B}$ signalling $(37,38)$. Therefore, unsaturated fatty acids in the GB extract might prevent LPS or palmitate-induced $\mathrm{NF}-\kappa \mathrm{B}$ activation, ER stress, and subsequent production of pro-inflammatory cytokines and inflammasome complex formation. 
A

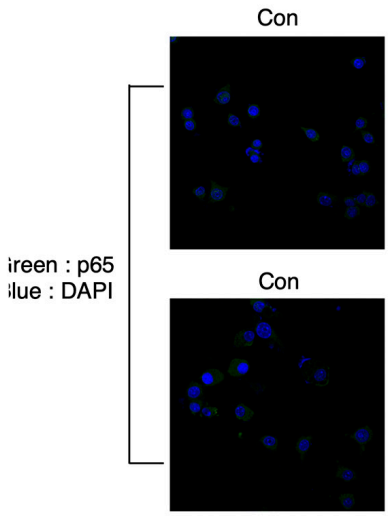

B

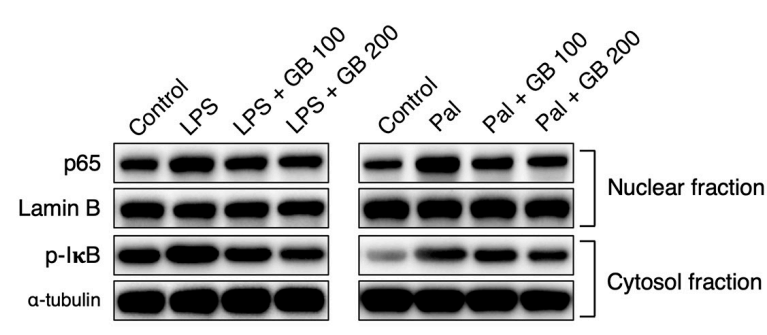

LPS + GB100

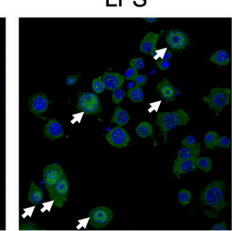

$\mathrm{Pal}$

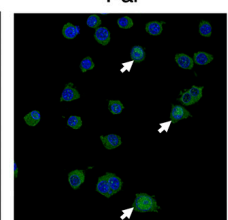

$\mathrm{Pal}+\mathrm{GB} 100$
LPS + GB200
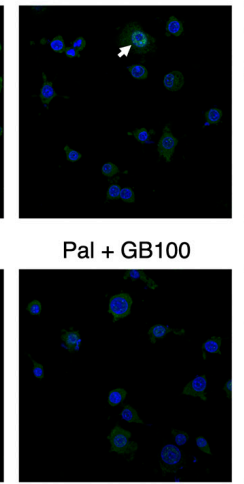

C

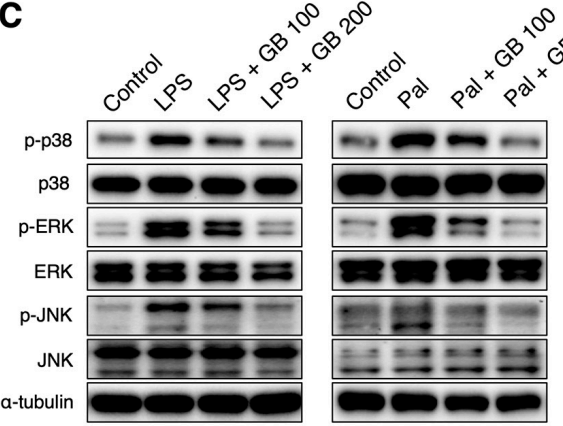

Figure 4. GB extract decreases NF- $\mathrm{kB}$ signalling, as well as MAP kinase phosphorylation. (A) After co-treatment with LPS (50 ng/ml), Pal (250 $\mu$ M) and GB extract (100 and $200 \mu \mathrm{g} / \mathrm{ml}$ ), translocation of p65 was determined using a p65 antibody and an Alexa-Fluor 488-conjugated anti-rabbit antibody (magnification, $\mathrm{x} 400$ ). Nuclei were counterstained with DAPI. p65 translocation into the nucleus is marked with arrows. Representative western blots were performed for (B) p65 in the nuclear fraction and IкB phosphorylation in the cytosol fraction, and (C) MAP kinase (p38, JNK and ERK) phosphorylation. All the experiments were performed in triplicates. GB, Gryllus bimaculatus; LPS, lipopolysaccharide; Pal, palmitate; Con, control; p-, phosphorylated.

A
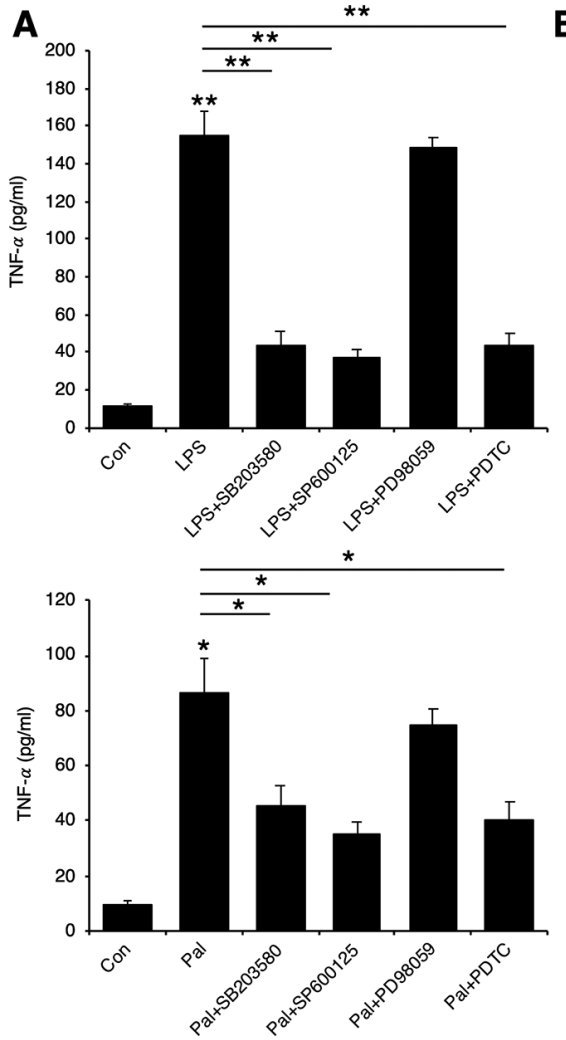

B
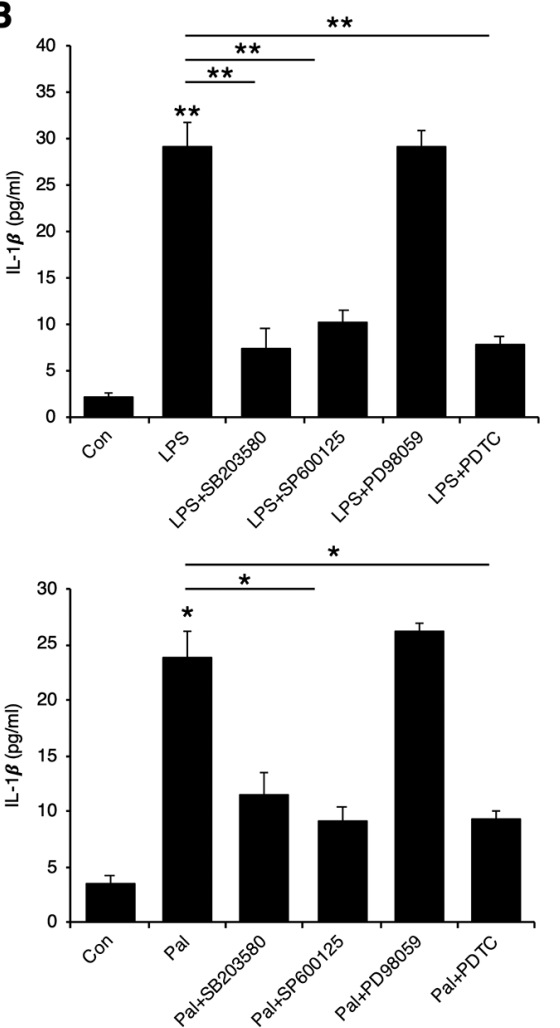

C
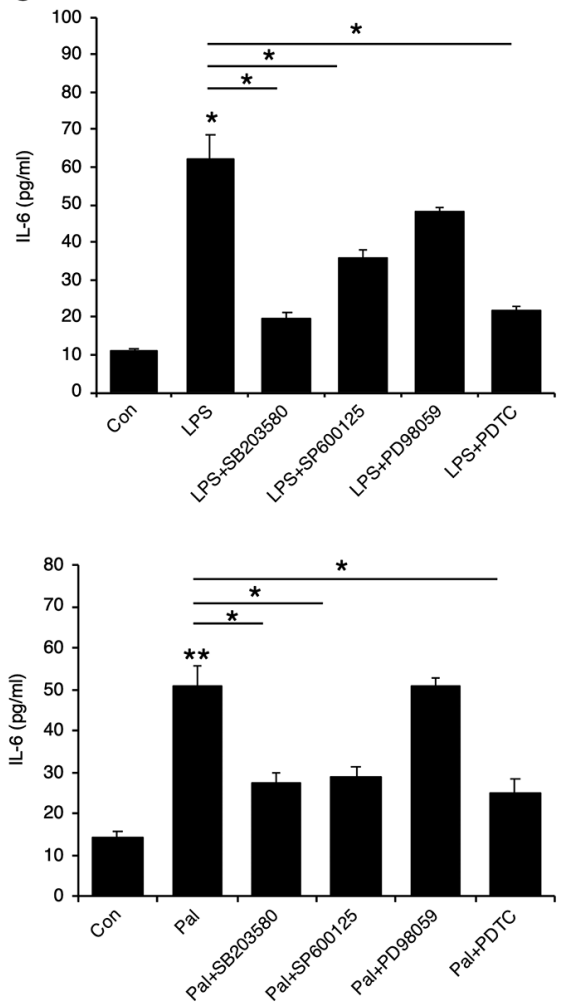

Figure 5. Both MAP kinase activation and NF- $\mathrm{kB}$ signalling serve a critical role in LPS- or Pal-induced cytokine secretion. After co-treatment with LPS $(50 \mathrm{ng} / \mathrm{ml})$ or Pal $(250 \mu \mathrm{M})$ and SB203580 (p38 inhibitor; $10 \mu \mathrm{M})$, SP600125 (JNK inhibitor; $10 \mu \mathrm{M})$, PD98059 (ERK inhibitor; $10 \mu \mathrm{M})$ or PDTC (NF- $\mathrm{B}$ inhibitor; $10 \mu \mathrm{M}$ ), (A) TNF- $\alpha$, (B) IL-1 $\beta$ and (C) IL-6 expression levels in RAW264.7 cell culture medium were measured using an ELISA kit. The values are expressed as the mean \pm SEM ( $\mathrm{n}=3)$. ${ }^{*} \mathrm{P}<0.05 ;{ }^{* *} \mathrm{P}<0.01$. GB, Gryllus bimaculatus; LPS, lipopolysaccharide; Pal, palmitate; Con, control; PDTC, pyrrolidinedithiocarbamate ammonium. 

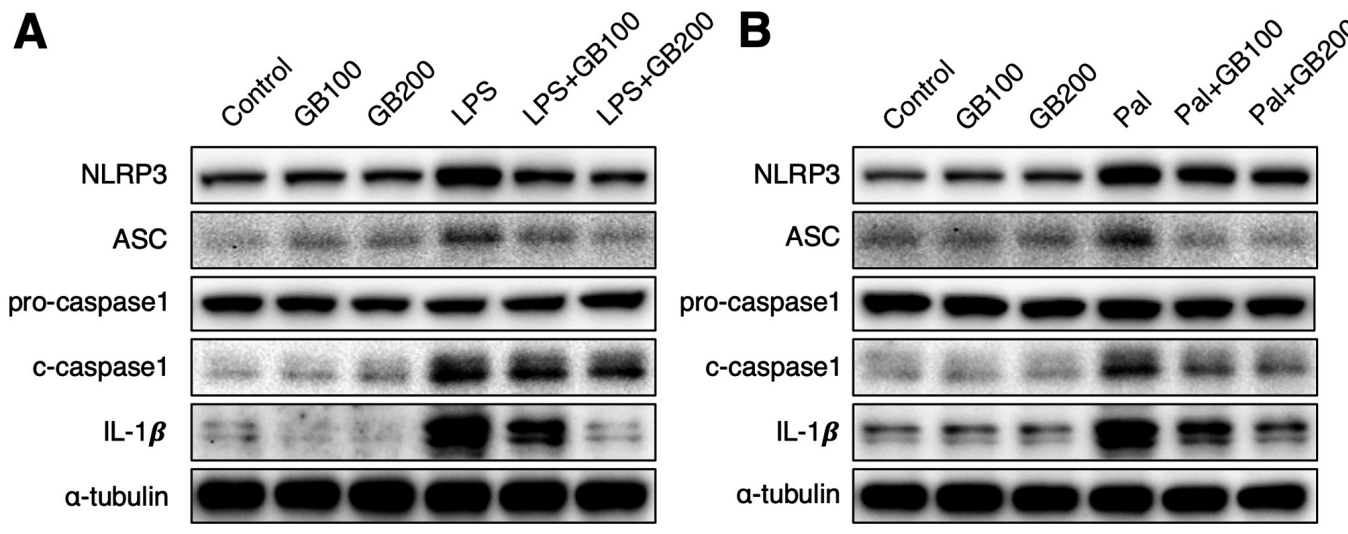

Figure 6. GB extract decreases LPS- or Pal-induced inflammasome complex formation. Representative western blots of the indicated proteins upon (A) LPS $(50 \mathrm{ng} / \mathrm{ml})$ or (B) Pal $(250 \mu \mathrm{M})$ treatment in RAW264.7 cells co-incubated with GB extract (100 and $200 \mu \mathrm{g} / \mathrm{ml})$. All the experiments were performed in triplicates. GB, Gryllus bimaculatus; LPS, lipopolysaccharide; Pal, palmitate; NLRP3, NOD-like receptor family pyrin domain containing 3; ASC, apoptosis-associated speck-like protein containing a caspase-recruitment domain; c-, cleaved.

A

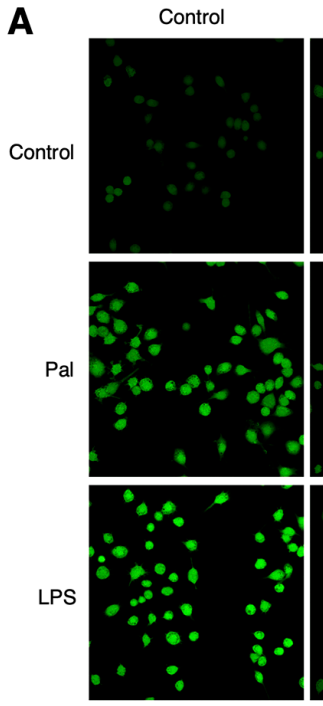

B

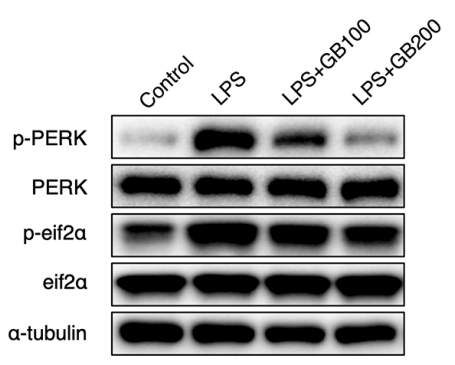

GB200
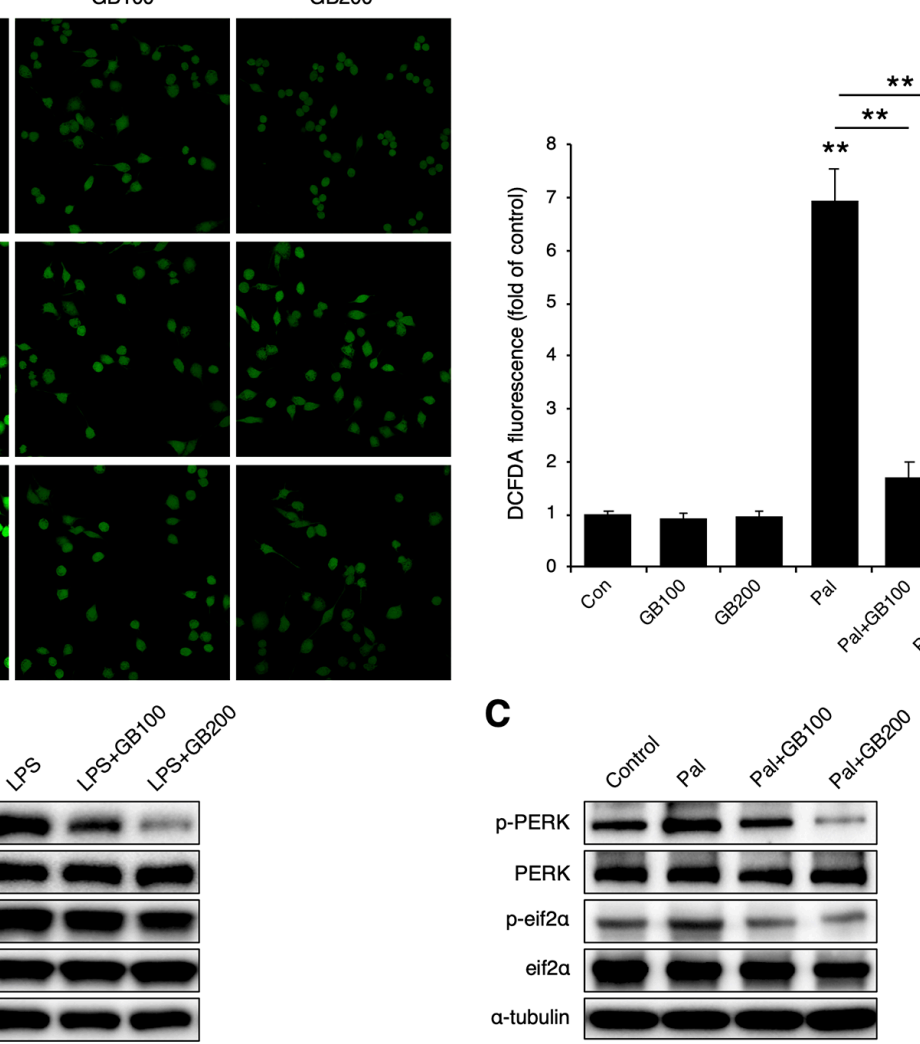

Figure 7. GB extract decreases LPS- or Pal-induced generation of ROS and endoplasmic reticulum stress. (A) After co-treatment with LPS (50 ng/ml), Pal $(250 \mu \mathrm{M})$ and GB extract (100 and $200 \mu \mathrm{g} / \mathrm{ml})$, ROS generation was evaluated (left panel; magnification, x400) and quantified (right panel). Representative western blots of the indicated proteins in (B) LPS- $(50 \mathrm{ng} / \mathrm{ml})$ or (C) Pal-treated ( $250 \mu \mathrm{M})$ RAW264.7 cells co-incubated with the GB extract (100 and $200 \mu \mathrm{g} / \mathrm{ml})$. The values are expressed as the mean \pm SEM $(n=3) .{ }^{* *} \mathrm{P}<0.01$. GB, Gryllus bimaculatus; LPS, lipopolysaccharide; Pal, palmitate; Con, control; ROS, reactive oxygen species; p-, phosphorylated; DCFDA, 2',7'-dichlorofluorescin diacetate; PERK, protein kinase RNA-like ER kinase; eif2 $\alpha$, eukaryotic initiation factor $2 \alpha$.

Some edible insects have also been known to inhibit inflammation when taken as food. For example, Tenebrio molitor and Allomyrina dichotoma reduce not only the high fat diet-induced steatohepatitis, but also hepatic inflammation (39). GB also has protective effects against alcohol-induced liver damage (15) and chronic arthritis (14). Tenebrio molitor has antioxidant and anti-inflammatory effects, and its composition is well studied; it contains various essential amino acids, unsaturated fatty acids, tocopherol and squalene (40) which may be contributing to these beneficial effects. Tenebrio molitor, Gryllodes sigillatus and Schistocerca gregaria have anti-inflammatory and antioxidant effects (41). Similarly, GB also has high amounts of unsaturated fatty acid, which might affect the anti-inflammatory effect, reduce ROS generation and decrease LPS or palmitate-induced cell death. 

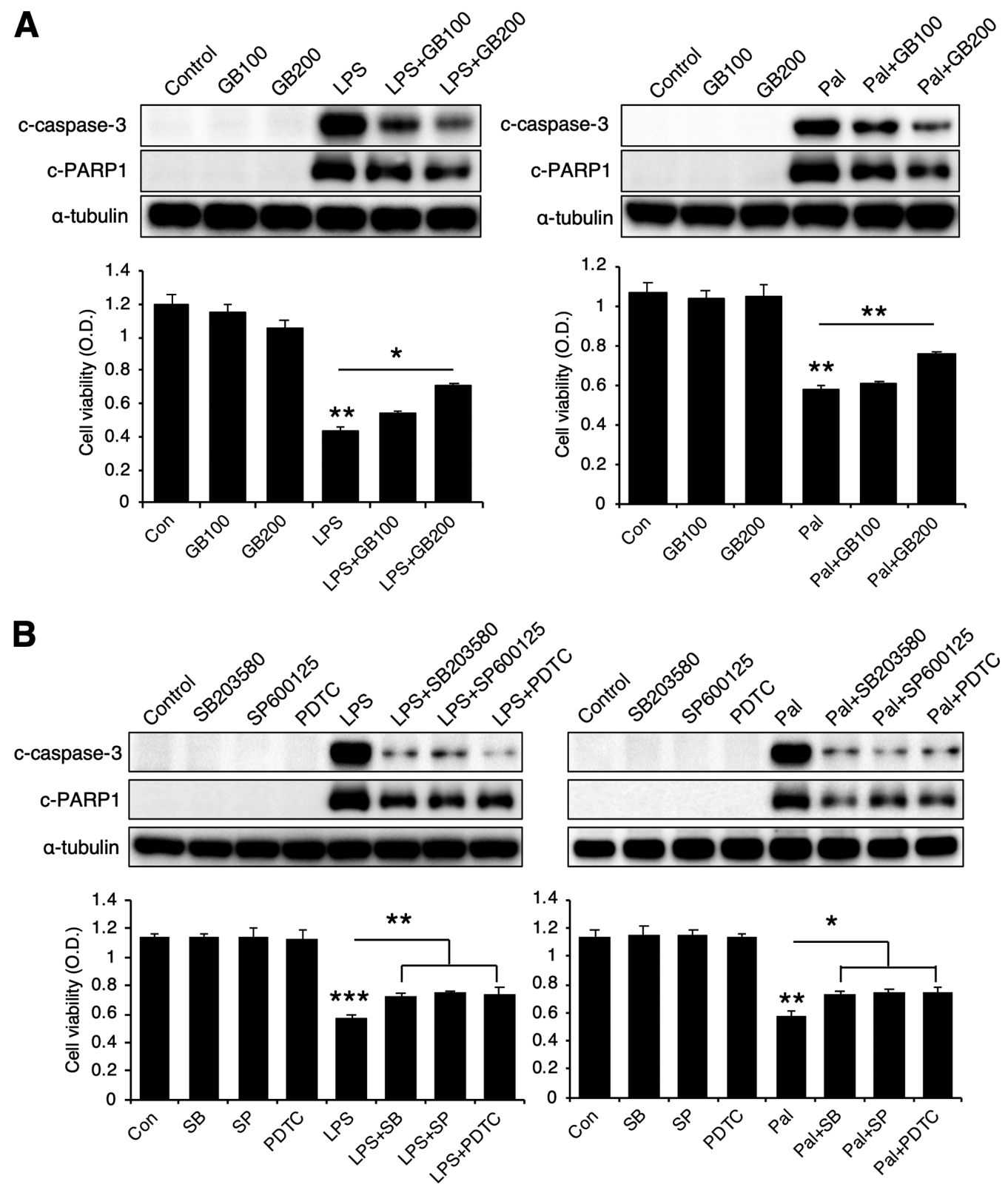

Figure 8. GB extract protects against LPS- or Pal-induced cytotoxicity. (A) Representative western blots of c-caspase-3 and c-PARP1, and MTT cell viability in LPS- $(50 \mu \mathrm{g} / \mathrm{ml})$ or Pal-treated ( $2 \mathrm{mM})$ RAW264.7 cells co-incubated with GB extract (100 and $200 \mu \mathrm{g} / \mathrm{ml})$. (B) Representative western blots of c-caspase-3 and c-PARP1, and MTT cell viability in LPS- $(5 \mu \mathrm{g} / \mathrm{ml})$ or Pal-treated $(2 \mathrm{mM})$ RAW264.7 cells co-incubated with either $10 \mu \mathrm{M} \mathrm{SB} 203580$ (p38 inhibitor), $10 \mu \mathrm{M}$

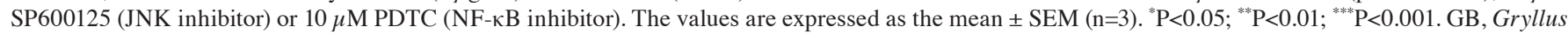
bimaculatus; LPS, lipopolysaccharide; Pal, palmitate; Con, control; c-, cleaved; PDTC, pyrrolidinedithiocarbamate ammonium; OD, optical density.

In conclusion, GB may potentially be one of the beneficial foods for controlling macrophage inflammatory processes, ROS generation, ER stress and cell death; it may also prevent diseases related to oxidative stress and inflammation. Thus, it can be used as a functional food in conditions of oxidative stress and inflammation.

\section{Acknowledgements}

Not applicable.

\section{Funding}

The present study was supported by the Basic Science Research Program through the National Research Foundation of Korea funded by the Ministry of Education (grant no. NRF-2019R1I1A1A01041076).

\section{Availability of data and materials}

The datasets used and/or analyzed during the current study are available from the corresponding author on reasonable request.

\section{Authors' contributions}

WJP and JSH contributed to the conception and design of the study. WJP and JSH performed the experiments and confirmed the authenticity of the raw data. WJP contributed to the acquisition of data and wrote the manuscript. WJP and 
JSH reviewed and edited the manuscript. All authors read and approved the final version of the manuscript.

\section{Ethics approval and consent to participate}

Not applicable.

\section{Patient consent for publication}

Not applicable.

\section{Competing interests}

The authors declare that they have no competing interests.

\section{References}

1. Korbecki J and Bajdak-Rusinek K: The effect of palmitic acid on inflammatory response in macrophages: An overview of molecular mechanisms. Inflamm Res 68: 915-932, 2019.

2. Lancaster GI, Langley KG, Berglund NA, Kammoun HL, Reibe S, Estevez E, Weir J, Mellett NA, Pernes G, Conway JR, et al: Evidence that TLR4 is not a receptor for saturated fatty acids but mediates lipid-induced inflammation by reprogramming macrophage metabolism. Cell Metab 27: 1096-1110.e5, 2018.

3. Shen C, Ma W, Ding L, Li S, Dou X and Song Z: The TLR4-IRE1 $\alpha$ pathway activation contributes to palmitate-elicited lipotoxicity in hepatocytes. J Cell Mol Med 22: 3572-3581, 2018.

4. Yu W, Zhang X, Wu H, Zhou Q, Wang Z, Liu R, Liu J, Wang X and Hai C: HO-1 is essential for tetrahydroxystilbene glucoside mediated mitochondrial biogenesis and anti-inflammation process in LPS-treated RAW264.7 macrophages. Oxid Med Cell Longev 2017: 1818575, 2017.

5. Rathinam VA, Vanaja SK and Fitzgerald KA: Regulation of inflammasome signaling. Nat Immunol 13: 333-342, 2012.

6. de Zoete MR, Palm NW, Zhu S and Flavell RA: Inflammasomes Cold Spring Harb Perspect Biol 6: a016287, 2014.

7. Baek HS, Min HJ, Hong VS, Kwon TK, Park JW, Lee J andKim S: Anti-inflammatory effects of the novel PIM kinase inhibitor KMU-470 in RAW 264.7 cells through the TLR4-NF-кB-NLRP3 pathway. Int J Mol Sci 21: 5138, 2020

8. Zhou H, Feng L, Xu F, Sun Y, Ma Y, Zhang X, Liu H, Xu G, Wu X, Shen Y, et al: Berberine inhibits palmitate-induced NLRP3 inflammasome activation by triggering autophagy in macrophages: A new mechanism linking berberine to insulin resistance improvement. Biomed Pharmacother 89: 864-874, 2017.

9. Wickliffe KE, Leppla SH and Moayeri M: Anthrax lethal toxin-induced inflammasome formation and caspase- 1 activation are late events dependent on ion fluxes and the proteasome. Cell Microbiol 10: 332-343, 2008.

10. Peng Y, French BA, Tillman B, Morgan TR and French SW: The inflammasome in alcoholic hepatitis: Its relationship with Mallory-Denk body formation. Exp Mol Pathol 97: 305-313, 2014.

11. Woolbright BL and Jaeschke H: Role of the inflammasome in acetaminophen-induced liver injury and acute liver failure. J Hepatol 66: 836-848, 2017.

12. Zhang L, Xu C, Chen X, Shi Q, Su W and Zhao H: SOCS-1 Suppresses inflammation through inhibition of NALP3 inflammasome formation in smoke inhalation-induced acute lung injury. Inflammation 41: 1557-1567, 2018.

13. Moossavi M, Parsamanesh N, Bahrami A, Atkin SL and Sahebkar A: Role of the NLRP3 inflammasome in cancer. Mol Cancer 17: 158, 2018.

14. Ahn MY, Han JW, Hwang JS, Yun EY and Lee BM: Anti-inflammatory effect of glycosaminoglycan derived from Gryllus bimaculatus (a type of cricket, insect) on adjuvant-treated chronic arthritis rat model. J Toxicol Environ Health A 77: $1332-1345,2014$

15. Hwang BB, Chang MH, Lee JH, Heo W, Kim JK, Pan JH, Kim YJ and Kim JH: The edible insect Gryllus bimaculatus protects against gut-derived inflammatory responses and liver damage in mice after acute alcohol exposure. Nutrients 11: 857, 2019.
16. Park SA, Lee GH, Lee HY, Hoang TH and Chae HJ: Glucose-lowering effect of Gryllus bimaculatus powder on streptozotocin-induced diabetes through the AKT/mTOR pathway. Food Sci Nutr 8: 402-409, 2019

17. Garcés R and Mancha M: One-step lipid extraction and fatty acid methyl esters preparation from fresh plant tissues. Anal Biochem 211: 139-143, 1993.

18. Ajuwon KM and Spurlock ME: Palmitate activates the NF-kappaB transcription factor and induces IL-6 and TNFalpha expression in 3T3-L1 adipocytes. J Nutr 135: 1841-1846, 2005.

19. Yoon J, Um HN, Jang J, Bae YA, Park WJ, Kim HJ, Yoon MS, Chung IY and Jung Y: Eosinophil activation by Toll-like receptor 4 ligands regulates macrophage polarization. Front Cell Dev Biol 7: 329, 2019

20. Wehinger S, Ortiz R, Díaz MI, Aguirre A, Valenzuela M, Llanos P, Mc Master C, Leyton L and Quest AF: Phosphorylation of caveolin-1 on tyrosine-14 induced by ROS enhances palmitate-induced death of beta-pancreatic cells. Biochim Biophys Acta 1852: 693-708, 2015.

21. Vogel SN, Marshall ST and Rosenstreich DL: Analysis of the effects of lipopolysaccharide on macrophages: Differential phagocytic responses of $\mathrm{C} 3 \mathrm{H} / \mathrm{HeN}$ and $\mathrm{C} 3 \mathrm{H} / \mathrm{HeJ}$ macrophages in vitro. Infect Immun 25: 328-336, 1979.

22. Kim MH, Ahn HK, Lee EJ, Kim SJ, Kim YR, Park JW and Park WJ: Hepatic inflammatory cytokine production can be regulated by modulating sphingomyelinase and ceramide synthase 6. Int J Mol Med 39: 453-462, 2017.

23. Oh AR, Sohn S, Lee J, Park JM, Nam KT, Hahm KB, Kim YB, Lee HJ and Cha JY: ChREBP deficiency leads to diarrhea-predominant irritable bowel syndrome. Metabolism 85: 286-297, 2018

24. Livak KJ and Schmittgen TD: Analysis of relative gene expression data using real-time quantitative PCR and the 2(-Delta Delta C(T)) method. Methods 25: 402-408, 2001.

25. Morgan DM: Tetrazolium (MTT) assay for cellular viability and activity. Methods Mol Biol 79: 179-183, 1998

26. Tang S, Shen XY, Huang HQ, Xu SW, Yu Y, Zhou CH, Chen SR, Le K, Wang YH and Liu PQ: Cryptotanshinone suppressed inflammatory cytokines secretion in RAW264.7 macrophages through inhibition of the NF- $\kappa$ B and MAPK signaling pathways. Inflammation 34: 111-118, 2011.

27. Wang L, Chen Y, Li X, Zhang Y, Gulbins E and Zhang Y: Enhancement of endothelial permeability by free fatty acid through lysosomal cathepsin B-mediated Nlrp3 inflammasome activation. Oncotarget 7: 73229-73241, 2016.

28. Yang HL, Lin SW, Lee CC, Lin KY, Liao CH, Yang TY, Wang HM, Huang HC, Wu CR and Hseu YC: Induction of Nrf2-mediated genes by Antrodia salmonea inhibits ROS generation and inflammatory effects in lipopolysaccharide-stimulated RAW264.7 macrophages. Food Funct 6: 230-241, 2015.

29. Wu X, Gao H, Hou Y, Yu J, Sun W, Wang Y, Chen X, Feng Y, $\mathrm{Xu} \mathrm{QM}$ and Chen X: Dihydronortanshinone, a natural product, alleviates LPS-induced inflammatory response through NF- $\mathrm{KB}$, mitochondrial ROS, and MAPK pathways. Toxicol Appl Pharmacol 355: 1-8, 2018.

30. Duarte S, Arango D, Parihar A, Hamel P, Yasmeen R and Doseff AI: Apigenin protects endothelial cells from lipopolysaccharide (LPS)-induced inflammation by decreasing caspase-3 activation and modulating mitochondrial function. Int $\mathbf{J}$ Mol Sci 14: 17664-17679, 2013.

31. Kim DH, Cho YM, Lee KH, Jeong SW and Kwon OJ: Oleate protects macrophages from palmitate-induced apoptosis through the downregulation of CD36 expression. Biochem Biophys Res Commun 488: 477-482, 2017.

32. Liu X, Zeng X, Chen X, Luo R, Li L, Wang C, Liu J, Cheng J, $\mathrm{Lu} \mathrm{Y}$ and Chen Y: Oleic acid protects insulin-secreting INS-1E cells against palmitic acid-induced lipotoxicity along with an amelioration of ER stress. Endocrine 64: 512-524, 2019.

33. Zhang Y, Dong L, Yang X, Shi $\mathrm{H}$ and Zhang L: $\alpha$-Linolenic acid prevents endoplasmic reticulum stress-mediated apoptosis of stearic acid lipotoxicity on primary rat hepatocytes. Lipids Health Dis 10: 81, 2011.

34. Katsoulieris E, Mabley JG, Samai M, Green IC and Chatterjee PK: alpha-Linolenic acid protects renal cells against palmitic acid lipotoxicity via inhibition of endoplasmic reticulum stress. Eur J Pharmacol 623: 107-112, 2009.

35. Yu Y, Correll PH and Vanden Heuvel JP: Conjugated linoleic acid decreases production of pro-inflammatory products in macrophages: Evidence for a PPAR gamma-dependent mechanism. Biochim Biophys Acta 1581: 89-99, 2002. 
36. Medeiros-de-Moraes IM, Goncalves-de-Albuquerque CF, Kurz AR, Oliveira FM, de Abreu VH, Torres RC, Carvalho VF, Estato V, Bozza PT, Sperandio M, et al: Omega-9 Oleic acid, the main compound of olive oil, mitigates inflammation during experimental sepsis. Oxid Med Cell Longev 2018: 6053492, 2018.

37. Cheng WL, Lii CK, Chen HW, Lin TH and Liu KL: Contribution of conjugated linoleic acid to the suppression of inflammatory responses through the regulation of the NF-kappaB pathway. J Agric Food Chem 52: 71-78, 2004.

38. Harvey KA, Walker CL, Xu Z, Whitley P, Pavlina TM, Hise M, Zaloga GP and Siddiqui RA: Oleic acid inhibits stearic acid-induced inhibition of cell growth and pro-inflammatory responses in human aortic endothelial cells. J Lipid Res 51: 3470-3480, 2010.
39. Lee JY, Im AR, Shim KS, Ji KY, Kim KM, Kim YH and Chae S: Beneficial effects of insect extracts on nonalcoholic fatty liver disease. J Med Food 23: 760-771, 2020.

40. Son YJ, Choi SY, Hwang IK, Nho CW and Kim SH: Could defatted Mealworm (Tenebrio molitor) and Mealworm Oil Be Used as Food Ingredients? Foods 9: 40, 2020.

41. Zielińska E, Baraniak B and Karaś M: Antioxidant and Anti-inflammatory activities of hydrolysates and peptide fractions obtained by enzymatic hydrolysis of selected heat-treated edible insects. Nutrients 9: 970, 2017.

(i)(9) This work is licensed under a Creative Commons Attribution-NonCommercial-NoDerivatives 4.0 International (CC BY-NC-ND 4.0) License. 